\title{
The impact of prior urethral sling on artificial urinary sphincter outcomes
}

\author{
Matthew J. Ziegelmann, MD; Brian J. Linder, MD; Marcelino E. Rivera, MD; Boyd R. Viers, MD; \\ Daniel S. Elliott, $M D$
}

Department of Urology, Mayo Clinic, Rochester, MN, United States

Cite as: Can Urol Assoc J 2016;10(11-12):405-9. hitp://dx.doi.org/10.5489/cuai.3922

\section{Abstract}

Introduction: We sought to evaluate device outcomes in men who underwent primary artificial urinary sphincter (AUS) placement after failed male urethral sling (MUS).

Methods: We performed a retrospective chart review of 990 men who underwent an AUS procedure between 2003 and 2014. Of these, 540 were primary AUS placements, including 30 (5.5\%) with a history of MUS. AUS revisions and explantations were compared between men stratified by the presence of prior sling. Hazard ratios (HR) adjusting for competing risks were used to determine the association with prior sling and AUS outcomes (infection/ erosion, urethral atrophy, and mechanical malfunction), while overall device failure was estimated using Kaplan-Meier and Coxregression analysis.

Results: There was no significant difference in age, body mass index, prior prostatectomy, or pelvic radiation when stratified by history of MUS. However, patients with a history of MUS were more likely to have undergone prior collagen injection $(p=0.01)$. On univariate and multivariate analysis, prior MUS was not associated with device failure (HR 1.54; $p=0.27$ ). Three-year overall device survival did not significantly differ between those with and without prior MUS (70\% vs. $85 \% ; p=0.21)$. Also, there were no significant differences in the incidence of device infection/erosion, mechanical malfunction, and urethral atrophy.

Conclusions: AUS remains a viable treatment option for men with persistent or recurrent stress urinary incontinence after MUS. However, while not statistically significant, we identified a trend towards lower three-year device outcomes in patients with prior urethral sling. These findings indicate the need for longer-term studies to determine if slings pose an increased hazard.

\section{Introduction}

Stress urinary incontinence (SUI) is a known side effect of prostate cancer treatment, with estimated post-prostatectomy incontinence rates ranging from $5-50 \% .^{1-4}$ Treatment includes observation, pelvic floor training, urethral bulking agents, male urethral sling (MUS), and artificial urinary sphincter (AUS). Of these options, AUS remains the gold standard for the treatment of severe post-prostatectomy SUI. ${ }^{5-9}$

Urethral slings for the treatment of male SUI was first reported in the 1970 s. $^{1}$ Since that time, multiple sling systems have been developed. Van Bruwaene and colleagues recently performed an extensive review of the literature on the treatment of male SUI with slings or AUS. Given significant heterogeneity in the literature, they identified success rate for slings varying from 30-90\%, depending on the type of sling and definition of success. ${ }^{10}$

Several factors have been associated with persistent incontinence after MUS, including high preoperative pad weight, poor external sphincter coaptation on cystoscopy, and prior pelvic radiation or urethral surgery. ${ }^{10-12}$ Retrospective data suggests that patients without these risk factors have lower postoperative pad weights and higher patient satisfaction rates. ${ }^{11}$ Also, patient-reported subjective improvement in continence appears to correlate with objective improvements, such as pad weight. ${ }^{13}$

Despite success in appropriately selected patients, up to $20 \%$ of males treated with MUS for SUI may experience a decline in their degree of improvement over time. ${ }^{14,15}$ In those patients with persistent or recurrent SUI, treatment options include conservative management with pads or a condom catheter, repeat sling procedure, or AUS placement. Several small published series have reported improvements, such as pad reduction and higher quality of life scores, with a repeat sling procedure, and late incontinence recurrence after the primary sling seems to correlate with improved outcomes. ${ }^{16,17}$ However, many patients who desire surgical management of their SUI after failed sling, especially in those with early-onset incontinence or other risk factors for sling failure, may benefit from AUS placement in lieu of a repeat sling procedure.

To date, few authors have evaluated device-specific outcomes in patients undergoing AUS placement after prior sling, 
and there is little information available to counsel this unique set of patients. ${ }^{18,19}$ Herein, we sought to compare device-specific outcomes in patients undergoing primary AUS placement with and without a history of MUS for urinary incontinence.

\section{Methods}

After obtaining institutional review board approval, we retrospectively identified 990 AUS procedures performed at our institution from 2003-2014. Patients who declined research consent, had underlying neurologic disease, or were less than 18 years old were excluded. Here, we focused on the 540 patients who underwent primary AUS placement, including 30 patients (5.5\%) with a history of prior MUS for treatment of SUI. A fellowship-trained urologist performed all AUS implantations over the timeframe of the study (DSE). All AUS devices were AMS800 ${ }^{\mathrm{TM}}$ (Boston Scientific, Inc, Natick, MA, U.S.).

For all AUS placements, a perineal incision was used. The bulbar urethra is isolated circumferentially. The decision to incise, excise, or leave the previously placed urethral sling in situ was made intraoperatively, based on the location of the mesh and extent of peri-urethral scarring. In cases of difficult urethral dissection, a transcorporal approach was used, as has been previously described. ${ }^{20,21}$ An abdominal reservoir was placed via a separate abdominal incision, and this was filled with $22 \mathrm{cc}$ of iso-osmotic contrast.

Patient followup and evaluations were performed by charts reviews, mailed questionnaires, and subsequent clinic visits. All patients were evaluated six weeks postoperatively for device activation. Following this, patients are typically followed symptomatically and, as part of our ongoing departmental registry, patients are contacted prospectively via mailing regarding their device.
The primary outcome in this study was the rate of secondary surgery after AUS placement for urethral atrophy, mechanical failure, and device infection/erosion. Continuous features were summarized with medians and interquartile ranges (IQR). Categorical features were summarized with frequency counts and percentages. Device survival was estimated as time from AUS implantation to subsequent repeat surgery (including explantation or device revision for any reason) using Kaplan-Meier survival analysis and cumulative incidence analysis. Most recent followup was defined as the date of subsequent surgery or most recent clinical followup in those patients who did not undergo repeat surgery. Statistical analysis was performed using JMP software package (SAS Institute, Inc. Cary, NC, U.S.).

\section{Results}

Clinical/demographic features for the 540 primary AUS placements stratified by the presence of a prior urethral sling are shown in Table 1. There was no significant difference in age or the presence of medical comorbidities. More than $87 \%$ of patients had a history of radical prostatectomy and there was no significant difference in the rates of additional cancer treatments, including radiation and androgen-deprivation therapy. Notably, patients who underwent prior MUS had higher rates of urethral collagen injection for SUI compared to those without (23\% vs. 9\%; $\mathrm{p}=0.01$ ). Additionally, the median followup was significant longer in those patients without a history of MUS (3.2 years compared with 1.8 years; $p=0.008$ ).

Data related to the 30 patients with prior MUS are shown in Table 2. These patients were more likely to receive their sling in the later part of the timeframe that we analyzed. Specifically, over $65 \%$ of patients with a history of

\begin{tabular}{|c|c|c|c|c|}
\hline & Without sling $(n=510)$ & With sling $(n=30)$ & Overall $(n=540)$ & p value \\
\hline \multicolumn{5}{|l|}{ Age } \\
\hline Median (IQR) & $71.3(66.1 ; 75.8)$ & $70.6(66.4 ; 79.5)$ & $71.3(66.1 ; 75.9)$ & 0.63 \\
\hline \multicolumn{5}{|l|}{ BMI } \\
\hline Median (IQR) & $28.9(26.5 ; 32.1)$ & $27.8(26.6 ; 31.1)$ & $28.8(26.6 ; 32.0)$ & 0.35 \\
\hline Hypertension (\%) & $348(68.5)$ & $18(60.0)$ & $366(68.0)$ & 0.30 \\
\hline Diabetes (\%) & $90(17.7)$ & $3(10.0)$ & $92(17.3)$ & 0.28 \\
\hline Cerebrovascular accident (\%) & $23(4.5)$ & $1(3.3)$ & $23(4.5)$ & 0.76 \\
\hline Coronary disease (\%) & $132(26.0)$ & $7(23.3)$ & $139(25.8)$ & 0.75 \\
\hline Radiation (\%) & $227(57.9)$ & $19(67.9 \%)$ & $246(58.6 \%)$ & 0.30 \\
\hline Androgen deprivation (\%) & $85(17.2)$ & $6(23.1)$ & $91(17.5)$ & 0.45 \\
\hline Prostatectomy (\%) & $411(87.1)$ & $27(93.1)$ & $438(87.4)$ & 0.34 \\
\hline Collagen $(\%)$ & $46(9.0)$ & $7(23.3)$ & $53(9.8)$ & 0.01 \\
\hline \multicolumn{5}{|l|}{ Followup } \\
\hline Median (IQR) & $3.2(0.0-12.0)$ & $1.8(0.1-10.0)$ & $3.0(0.0-12.0)$ & 0.008 \\
\hline
\end{tabular}




\begin{tabular}{lc}
\hline Table 2. Urethral sling patient cohort (n=30) & \\
\hline Year of AUS surgery & $\mathbf{n}(\%)$ \\
\hline 2003 & $2(6.7)$ \\
2004 & $0(0.0)$ \\
2005 & $1(3.3)$ \\
2006 & $2(6.7)$ \\
2007 & $1(3.3)$ \\
2008 & $1(3.3)$ \\
2009 & $2(6.7)$ \\
2010 & $1(3.3)$ \\
2011 & $3(10.0)$ \\
2012 & $7(23.3)$ \\
2013 & $6(20.0)$ \\
2014 & $4(13.3)$ \\
Sling type & \\
Coloplast Virtue & $4(13.3)$ \\
AMS AdVance & $13(43.3)$ \\
AMS InVance & $3(10.0)$ \\
Unknown & $10(33.3)$ \\
Intraoperative sling management & \\
Incision/partial excision & $11(36.7)$ \\
Urethrolysis & $10(33.3)$ \\
None & $9(30.0)$ \\
\hline AUS: artificial urinary sphincter. & \\
\hline
\end{tabular}

MUS underwent primary AUS placement between 2011 and 2014. AMS AdVance ${ }^{\mathrm{TM}}$ slings were the most common device encountered, comprising over $43 \%$ of our cohort. Interestingly, $70 \%$ of patients required intraoperative sling management in the form of sling excision/incision (37\%) or extensive urethrolysis (33\%). While not shown here, there was no significant difference in the incidence of device revision based on the need for sling management or urethrolysis (hazard ratio [HR] 1.2; $\mathrm{p}=0.27$ ). On univariate analysis, overall device failure was similar when patients were stratified by the presence of prior MUS $(p=0.20)$. In contrast, coronary artery disease was associated with a significant increase in the risk for device failure (HR 1.62; $\mathrm{p}=0.02)$ (Table 3).

As shown in Fig. 1, three-year device survival was $85 \%$ for patients without a history of MUS compared with $70 \%$ for patients with prior MUS. However, this did not reach statistical significance $(p=0.21)$. Also, given the potential impact that prior slings may have on specific device outcomes, additional independent cumulative incidence models were created for infection/erosion, mechanical failure, and urethral atrophy. As shown in Fig. 2, there was no significant difference in these specific device outcomes based on history of MUS.

\section{Discussion}

Here, we evaluated AUS device outcomes in patients with a history of MUS in order to more appropriately counsel patients regarding postoperative expectations in this unique

\begin{tabular}{|c|c|c|c|c|}
\hline & \multicolumn{4}{|c|}{ Overall AUS failure } \\
\hline & \multicolumn{2}{|c|}{ Univariate } & \multicolumn{2}{|c|}{ Multivariate } \\
\hline & HR (95\% Cl) & $\begin{array}{c}\mathbf{p} \\
\text { value }\end{array}$ & HR (95\% Cl) & $\begin{array}{c}p \\
\text { value }\end{array}$ \\
\hline Age & $\begin{array}{c}1.025 \\
(0.99 ; 1.05)\end{array}$ & 0.06 & & \\
\hline BMI & $\begin{array}{c}0.98 \\
(0.93 ; 1.02)\end{array}$ & 0.28 & & \\
\hline Hypertension & $\begin{array}{c}1.26 \\
(0.84 ; 1.89)\end{array}$ & 0.26 & & \\
\hline Diabetes & $\begin{array}{c}1.38 \\
(0.86 ; 2.22)\end{array}$ & 0.18 & & \\
\hline $\begin{array}{l}\text { Cerebrovascular } \\
\text { accident }\end{array}$ & $\begin{array}{c}1.00 \\
(0.37 ; 2.72)\end{array}$ & 1.00 & & \\
\hline Coronary disease & $\begin{array}{c}1.64 \\
(1.10 ; 2.44)\end{array}$ & 0.01 & $\begin{array}{c}1.62 \\
(1.09 ; 2.41)\end{array}$ & 0.02 \\
\hline Radiation & $\begin{array}{c}1.22 \\
(0.81 ; 1.82)\end{array}$ & 0.34 & & \\
\hline $\begin{array}{l}\text { Androgen } \\
\text { deprivation }\end{array}$ & $\begin{array}{c}1.13 \\
(0.68 ; 1.89)\end{array}$ & 0.63 & & \\
\hline Prostatectomy & $\begin{array}{c}0.60 \\
(0.345 ; 1.04)\end{array}$ & 0.07 & & \\
\hline Collagen & $\begin{array}{c}1.11 \\
(0.62 ; 1.99)\end{array}$ & 0.71 & & \\
\hline Prior sling & $\begin{array}{c}1.63 \\
(0.77 ; 3.46)\end{array}$ & 0.20 & $\begin{array}{c}1.54 \\
(0.71 ; 3.32)\end{array}$ & 0.27 \\
\hline
\end{tabular}

AUS: artificial urinary sphincter; BMI: body mass index; Cl: confidence interval; HR: hazard ratio.

cohort. We found that patients who underwent MUS for the treatment of SUI prior to primary AUS placement had no significant difference in overall three-year survival than those patients without a prior sling procedure. Additionally, no significant differences were identified in specific device outcomes, including device infection/erosion, mechanical malfunction, and urethral atrophy. This information is useful when counselling patients on treatments for SUI.

Liu and colleagues recently evaluated the American Board of Urology six-month case log data for certifying urologists between 2003 and 2013. Slings represented 48\% of the male anti-incontinence procedures performed, while AUS represented $52 \%$. Notably, sling procedures as a percentage of all procedure performed increased by $13 \%$ over the 10-year period. ${ }^{22}$ Reasons for this trend include ease of placement and patient preference. ${ }^{10}$ In fact, it appears that many patients may favour MUS over AUS, despite recommendations from the performing surgeon to pursue AUS placement. $^{23}$

Despite success with slings in a select group of patients, i.e., those with low preoperative pad weights, appropriate external sphincter coaptation on preoperative cystoscopy, and no history of prior radiation or urethral surgery, there are many patients who do not fit these criteria and are better served with AUS. ${ }^{10-12}$ Sturm and colleagues identified significantly lower postoperative pad weights and higher 


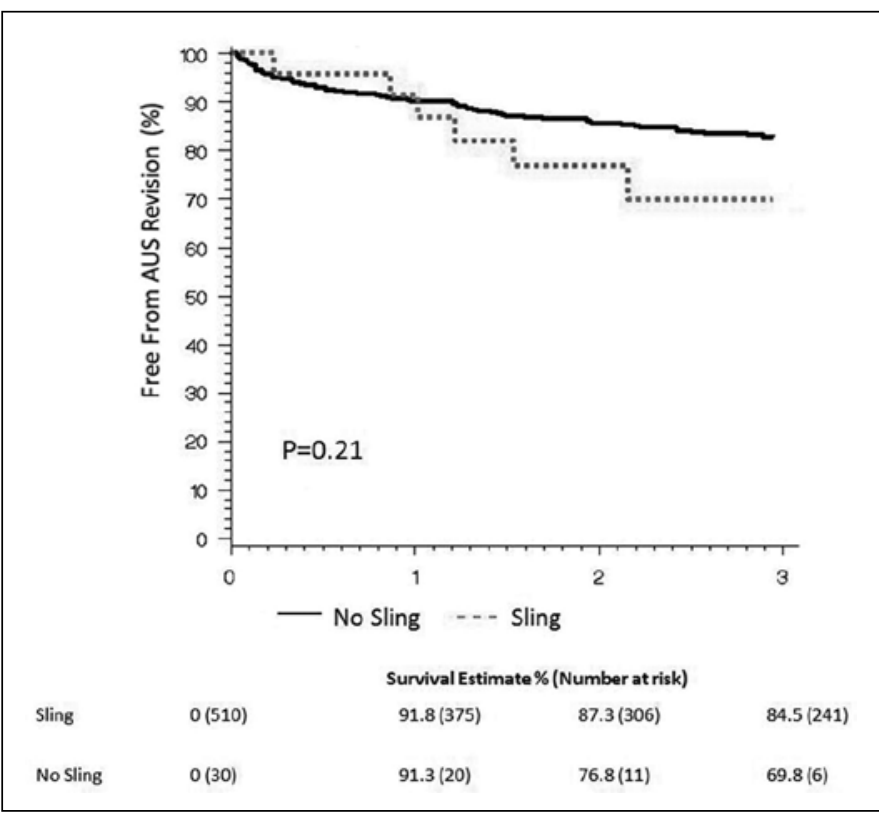

Fig. 1. Kaplan-Meier curve for overall device survival.

patient satisfaction rates after male urethral sling in "ideal" patients who fit into these criteria compared with "nonideal" patients with one or more risk factors. ${ }^{11}$ Importantly, even in the setting of initial improvement, some patients experience a decline in their degree of continence over time with slings. ${ }^{14,15}$

For those patients who desire surgery for recurrent or persistent incontinence, surgeons are faced with the decision to pursue a repeat sling or proceed to AUS placement. Repeat slings are successful in some patients, and an increased success rate has been reported in patients who present with recurrent incontinence further out from their initial MUS. ${ }^{16,17}$ On the other hand, outcomes associated with primary AUS placement after prior MUS in the setting of recurrent or persistent incontinence after initial sling placement has been the subject of few studies. ${ }^{18,19}$ Ajay and colleagues performed a retrospective analysis comparing outcomes in patients undergoing AUS vs. repeat sling after prior failed MUS. They identified a seven-fold difference in the rate of persistent incontinence in favour of primary AUS placement. ${ }^{24}$

Lentz and colleagues identified similar AUS device survival in patients with and without a prior sling, as well as excellent continence rates at a mean followup of 20.7 months. All prior devices were AdVance slings, and the authors report leaving all slings in situ at the time of primary AUS placement, with the cuff placed distally. ${ }^{18}$ In contrast, our experience involves patients with multiple types of prior slings placed by many different surgeons. We found significant peri-urethral reaction around the sling, requiring sling incision, excision, urethrolysis, or a combination of these maneuvers in $>70 \%$ of patients in order to correctly place the AUS cuff in the proximal bulbar urethra, which we feel offers patients the highest chance of treatment success.

AUS revision after previous infection or erosion has been associated with an increased risk for device-related complications, and we hypothesize that alterations to the urethral blood supply and peri-urethral tissue may be the underlying cause for the worse outcomes observed. ${ }^{25}$ Given the need for peri-urethral dissection and subsequent foreign body reaction with MUS, it seems plausible that these procedures would result in alterations to the urethral blood flow in a similar manner. Surprisingly, the current analysis did not identify a statistically significant difference in device infection/erosion or urethral atrophy in those patients with a history of prior sling. However, at three years, the overall device survival was $15 \%$ lower in the sling-patients. While not statistically significant, this is noteworthy and suggests that longer-term followup is necessary. Certain conditions, such as urethral atrophy, may present later as worsening of urinary incontinence. In our cohort, $65 \%$ of patients under-

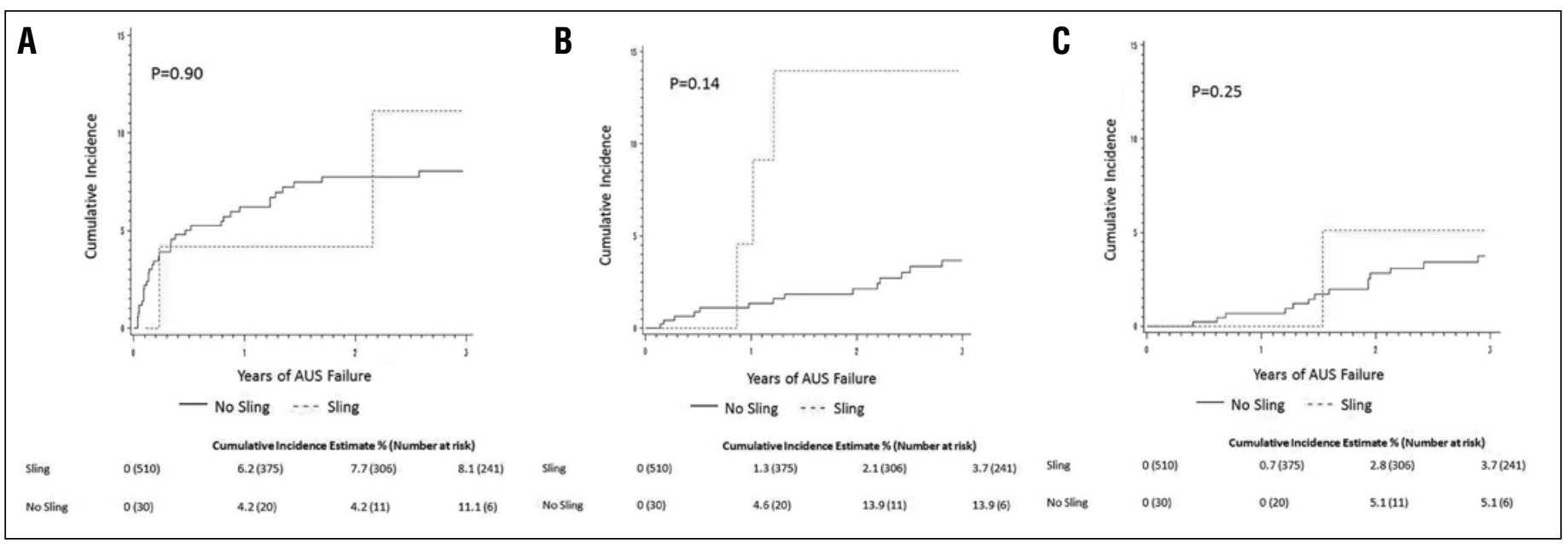

Fig 2. Cumulative-incidence curve for: (A) device infection/erosion; (B) mechanical malfunction; and (C) urethral atrophy. 
went sphincter placement after 2011, accounting for the shorter followup. This is not surprising, given the increasing rate of sling placement for male SUI, as noted earlier. ${ }^{22,26}$ As such, longer-term followup may help to delineate any significant difference in primary sphincter outcomes in those patients with a history of prior MUS.

Our study has limitations. This is a single-surgeon cohort from a high-volume tertiary care centre. The data may not be well-extrapolated to lower-volume practices. Additionally, given the nature of our practice, many of the slings were placed by outside surgeons. Specifically, the patient's preoperative clinical characteristics and intraoperative details at the time of MUS placement could not be assessed. As such, the role that these variables play in the eventual success with primary AUS could not be determined. Finally, patient followup was not standardized. In an attempt to account for the lack of standardized followup, we send out yearly prospective written correspondence to follow up on device status and gain information on functional outcomes.

\section{Conclusion}

In conclusion, primary AUS placement remains a viable treatment option for men with persistent or recurrent SUI after prior MUS. However, while not statistically significant, we identified a trend towards lower three-year device outcomes in patients with prior sling compared to those without. As such, longer-term and possibly multi-institutional studies are warranted; in the interim, patients should be counselled regarding the possible increased risk for device-related complications. Additionally, when counselling a patient with prior radiation therapy, higher volume urine leakage, and poor coaptation on cystoscopy, surgeons should give consideration to primary AUS over placement of a sling.

Competing interests: The authors report no competing personal or financial interests.

This paper has been peer-reviewed.

\section{References}

1. Jarvis TR, Sandhu JS. Management of urinary incontinence after radical prostatectomy. Curr Urol Rep 2014;15:421. http://dx.doi.org/10.1007/s11934-014-0421-6

2. Sacco E, Prayer-Galetti T, Pinto F, et al. Urinary incontinence after radical prostatectomy: Incidence by definition, risk factors, and temporal trend in a large series with a long-term followup. BJU Int 2006;97:1234-41. http://dx.doi.org/10.1111/i.1464-410X.2006.06185.x

3. Haglind E, Carlsson S, Stranne J, et al. Urinary incontinence and erectile dysfunction after robotic vs. open radical prostatectomy: A prospective, controlled, non-randomized trial. Eur Urology 2015;68:216-25. http://dx.doi.org/10.1016/j.eururo.2015.02.029

4. Kim PH, Pinheiro $\mathrm{LC}$, Atoria $\mathrm{CL}$, et al. Trends in the use of incontinence procedures after radical prostatectomy: A population-based analysis. J Urol 2013;189:602-8. http://dx.doi.org/10.1016/i. juro.2012.08.246
5. Linder BJ, Rivera ME, Ziegelmann MJ, et al. Long-term outcomes following artificial urinary sphincter placement: An analysis of 1082 cases at Mayo Clinic. Urology 2015;86:602-7. http://dx.doi.org/10.1016/i. urology.2015.05.029

6. Van der Aa F, Drake MJ, Kasyan GR, et al. The artificial urinary sphincter after a quarter of a century: A critical systematic review of its use in male non-neurogenic incontinence. Eur Urol 2013;63:681-9. http://dx.doi.org/10.1016/i.eururo.2012.11.034

7. Léon $P$, Chartier-Kastler $E$, Rouprêt $M$, et al. Long-term functional outcomes after artificial urinary sphincter implantation in men with stress urinary incontinence. BJU Int 2015;115:951-7. http://dx.doi. org/10.1111/bju.12848

8. Lai HH, Hsu El, Teh BS, et al. 13 years of experience with artificial urinary sphincter implantation at Baylor College of Medicine. J Urol 2007;177:1021-5. http://dx.doi.org/10.1016/i.juro.2006.10.062

9. Kim SP, Sarmast Z, Daignault $S$, et al. Long-term durability and functional outcomes among patients with artificial urinary sphincters: A 10-year retrospective review from the University of Michigan. J Urol 2008; 179:1912-6. http://dx.doi.org/10.1016/i.juro.2008.01.048

10. Van Bruwaene $S$, De Ridder D, Van der Aa F. The use of sling vs sphincter in post-prostatectomy urinary incontinence. BJU Int 2015;116:330-42. http://dx.doi.org/10.1111/bju.12976

11. Sturm RM, Guralnick ML, Stone AR, et al. Comparison of clinical outcomes between "ideal" and "nonideal" transobturator male sling patients for treatment of post-prostatectomy incontinence. Urology 2014;83:1186-8. http://dx.doi.org/10.1016/i.urology.2013.12.061

12. Kim SW, Walsh R, Berger Y, et al. Male readjustable sling (MRS) system for post-prostatectomy incontinence: Experiences of two centres. Urology 2016;88:195-200. http://dx.doi.org/10.1016/i.urology.2015.10.016

13. Gill BC, Swartz MA, Klein JB, et al. Patient perceived effectiveness of a new male sling as treatment for postprostatectomy incontinence. J Urol 2010;183:247-52. http://dx.doi.org/10.1016/i.juro.2009.08.159

14. Li H, Gill BC, Nowacki AS, et al. Therapeutic durability of the male transobturator sling: Mid-term patientreported outcomes. J Urol 2012;187:1331-5. http://dx.doi.org/10.1016/i.juro.2011.11.091

15. Zuckerman $\mathrm{JM}$, Edwards $B$, Henderson $\mathrm{K}$, et al. Extended outcomes in the treatment of male stress urinary incontinence with a transobturator sling. Urology 2014;83:939-45. http://dx.doi.org/10.1016/i.urology.2013.10.065

16. Martinez EJ, Zuckerman JM, Henderson K, et al. Evaluation of salvage male transobturator sling placement following recurrent stress urinary incontinence after failed transobturator sling. Urology 2015;85:478-82. http://dx.doi.org/10.1016/i.urology.2014.10.016

17. Soljanik I, Becker AJ, Stief CG, et al. Repeat retrourethral transobturator sling in the management of recurrent post-prostatectomy stress urinary incontinence after failed first male sling. Eur Urol 2010;58:767-72. http://dx.doi.org/10.1016/i.eururo.2010.08.034

18. Lentz $\mathrm{AC}$, Peterson $\mathrm{AC}$, Webster $\mathrm{GD}$. Outcomes following artificial sphincter implantation after prior unsuccessful male sling. J Urol 2012;187:2149-53. http://dx.doi.org/10.1016/i.juro.2012.01.119

19. Fisher MB, Aggarwal N, Vuruskan $\mathrm{H}$, et al. Efficacy of artificial urinary sphincter implantation after failed bone-anchored male sling for post-prostatectomy incontinence. Urology 2007;70:942-4. http://dx.doi. org/10.1016/j.urology.2007.07.022

20. Guralnick ML, Miller E, Toh KL, et al. Transcorporal artificial urinary sphincter cuff placement in cases requiring revision for erosion and urethral atrophy. J Urol 2002;167:2075-8; discussion 2079. http://dx.doi.org/10.1016/S0022-5347(05)65088-4

21. Magera JS Jr, Elliott DS. Tandem transcorporal artificial urinary sphincter cuff salvage technique: Surgical description and results. J Urol 2007;177:1015-9; discussion 1019-20. http://dx.doi.org/10.1016/i. juro.2006.10.052

22. Liu JS, et al. male sling and artificial urethral sphincter for male stress urinary incontinence amongst certifying American urologists. Urology 2015;193:e1097. http://dx.doi.org/10.1016/i.juro.2015.02.1846

23. Kumar A, Litt ER, Ballert KN, et al. Artificial urinary sphincter vs. male sling for post-prostatectomy incontinence — what do patients choose? J Urol 2009;181:231-5. http://dx.doi.org/10.1016/i. juro.2008.11.022

24. Ajay D, Zhang H, Gupta S, et al. The artificial urinary sphincter is superior to a secondary transobturator male sling in cases of a primary sling failure. J Urol 2015;194:1038-42. http://dx.doi.org/10.1016/j. juro.2015.04.106

25. Linder BJ, de Cogain M, Elliott D.S. Long-term device outcomes of artificial urinary sphincter reimplantation following prior explantation for erosion or infection. J Urol 2014;191:734-8. http://dx.doi. org/10.1016/i.juro.2013.08.089

26. Poon SA, Silberstein JL, Savage C, et al. Surgical practice patterns for male urinary incontinence: Analysis of case logs from certifying American urologists. J Urol 2012;188:205-10. hittp://dx.doi.org/10.1016/i. juro.2012.03.012

Correspondence: Dr. Matthew J. Ziegelmann , Department of Urology, Mayo Clinic, Rochester, MN, United States; ziegelmann.matthew@mayo.edu 